\title{
A philosophy of a clinically based medical ethics
}

\author{
David C Thomasma Program on Human Values and Ethics, University of Tennessee, Center for the \\ Health Sciences, Memphis, Tennessee, USA
}

\section{Author's abstract}

Pellegrino and Siegler have argued that medical ethics must be taught 'at the bedside', or clinically. This paper is an attempt to establish the need for clinical teaching of medical ethics both to medical students and to medical ethicists who are not physicians.

Through a critique of six positions regarding the aims of medical ethics, four principles are established which are the basis of a philosophy of education for medical ethics. The need for a clinically-based educational programme in medical ethics is thereby established, not on practical grounds, but on solid philosophical ones.

The paper concludes with practical examples of a clinically-based medical ethics programme following from the four principles.

Medical ethics has become a lively branch of medicine, philosophy, theology, law and related disciplines in the past twenty years. In fact the discipline has grown phenomenally. This growth has occurred in spite of some serious challenges to its helpfulness and eventual outcome. The development of medical ethics has now reached a stage which requires some articulation of its avenues for success and maturity.

As one step in such an articulation, I will present a thesis about the optimal growth of medical ethics. A simultaneous sketch of a clinical programme (or 'practicum' as we have called it) in medical ethics is discussed as a practical educational example of the thesis.

The thesis about medical ethics is, on the face of it, rather simple. The chance for helpful solutions to medical dilemmas and professional and personal accountability for making ethical decisions increases with an understanding of the medical situation. Mark Siegler has proposed a similar thesis, but has offered practical advantages rather than philosophical reasons for this approach. ${ }^{1}$ Since medicine is a practical, clinically based discipline, the thesis can be restated to read: medical ethics, in order to develop properly, should be clinically based. As a corollary, training for medical ethicists ought also to be clinically based. Physicians must, at the very least, be involved in a training programme to provide clinical experience for them. It is for this reason that the clinical practicum is described.

The thesis is developed in the first section. First,
I will examine a view about the aim and method $\overrightarrow{\partial f}$ medical ethics which poses a challenge to the thesis. By contrast, I will then offer arguments against this view and in support of the thesis. Five views and $\vec{r}-$ sponses will be covered. The second section contaighs substantiation of the thesis through an explanation of the clinical practicum. In other words, I intend the arguments presented to constitute a philosophy of medical ethics education.

\section{Challenges}

Challenges to the role, scope and development $\&_{f}$ medical ethics reveal that serious problems abogut its disciplinary status persist. Views about the aims and methods of medical ethics usually fall into ficke categories of increasing acceptance. The first category contains rejection of the possibility of helpful medical ethics; the second category contains views which highlight the application of ethieal principles to medical problems; in the third category, views of medical ethics as helpful in non-prescriptively ranking values are presented; the fourth category is composed of views which argue that medical ethics ought to propose policy recommengations; and the fifth category is composed of pos sttions which view medical ethics as an essential activity of medical practice. I will shorten the्क e categories as follows:

a) Rejections;

b) Application;

c) Ranking;

d) Policy recommendations;

e) Medical act.

My intention is to illustrate the categories examples culled from current thinkers. The focuts will be on their proposals regarding the aims and methods of medical ethics, and not the entirety of their arguments.

REJECTION

In addition to the many warnings by cautious heali professionals about the growing power of ethicists ${ }^{2}$ philosophers themselves have called into questien any role for philosophical ethics in medicine. Thips is done on two grounds. The first is the argumeef, posed by Alasdair MacIntyre, that philosophy cam help medicine very little since the cultural underpinning of medical ethics is too diffuse and pluresistic today for philosophy to organise. In his work, 
'The medical profession ought not therefore to look for solutions to philosophical theorising; what philosophy has to tell them is precisely why they cannot hope for solutions.' 8

It is clear from his arguments that Macintyre considers the proper aim and method of medical ethics to be organising principles from cultural values, applying them to medical problems, and appealing to them to resolve disputes. In his view, such organisation and appeal is now impossible because cultural pluralism marks the end of all rational discourse. ${ }^{4}$

The second ground for rejecting the possibility of a helpful medical ethics stems from an entirely different approach. Donald B Marquis notes that physicians are forced to make moral judgments without sufficient training in ethics. So, too, must philosophers make moral judgments without sufficient training in medicine. He doubts whether philosophers can acquire sufficient medical knowledge to offer helpful solutions:

In recent years physicians have discussed the ethics of treatment of neonates with spina bifida, a congenital spine defect. I don't really see how a philosopher can discuss such issues intelligently without an appreciation of the variations in pathology and the difficulties of prognosis in such cases. To understand such matters well involves a great deal of anatomy and physiology, knowing a great deal of pathology and acquiring a great deal of clinical experience. This - to say the least - is not done easily. Indeed, it is not clear it can be done by philosophers at all. If not, it is not clear that the philosopher concerned with medical ethics has any business writing about the ethics of spina bifida therapy. ${ }^{5}$

Marquis recognises that medical ethics ought to offer helpful solutions to cases, and further recognises that this requires clinical experience. His doubt is not about the establishment of principles, but rather, about the acquiring of clinical experience sufficient to offer helpful suggestions.

\section{CRITIQUE}

It is a truism to suggest that a variety of aims of a discipline contribute to the scope of its vitality. But in the case of medical ethics, some of the proposed aims contradict others. The first position that there are no ultimately valid moral principles, conflicts with all other subsequent positions; that the aim of medical ethics should be to rank values, that no solutions to immediate problems be posed. What sense can be made of the conflicting aims?

Positions taken in $a$ ) reflect a real understanding of the proper aim of medical ethics, ie, to contribute to solutions to difficult medical dilemmas. The first rejects this as a possibility on the grounds that ultimate moral principles are impossible in a pluralistic society. If one takes this objection seriously no moral judgement would be possible.

\section{Suggestion}

I suggest that moral principles should not be understood as the court of last appeal in ethical disputes. Instead ethical dilemmas must be resolved by attention to the limited norms of medical practice articulated by a philosophy of medicine (such as 'Do no harm'), patient values, and the clinical context. These, coupled with attention to general values, are sufficient to resolve most dilemmas posed in medical practice. The second position rejects the possibility of a helpful medical ethics, not on theoretical grounds, but practical ones. However, the arguments about the aims of medical ethics in $d)$ and $e$ ) are sufficiently strong to indicate the importance of teaching ethics clinically.

\section{Suggestion}

While difficult clinical medical ethics can be taught and learned. The structure of this process is spelled out in the concluding section of the paper.

\section{APPLICATION}

In this second category are found positions emphasising the application of ethical principles to the medical situation. Many medical ethicists fall into this category, eg, Ramsey, although I detect two separate strains. The first represents a thoroughgoing application of the methodology of normative ethics to medical ethics, and the second represents a cautious approach to suggesting solutions to problems.

An example of the first is Richard M Hare's analysis of abortion. He argues that a utilitarian analysis of issues and arguments is the best approach, and cites, as the proper method of medical ethics, the offering of canons of valid reasoning. " An example of the second is offered by Daniel Callahan. Most recently he warns of the danger of bifurcating medical ethics into two branches, citing backlash, jargon, and a demand for solutions as consequences of this bifurcation. The two paths Callahan sees in the future are orientation towards practical solutions and orientation towards exploring deeper issues affecting modern life. In his view, medical ethics does have an important future and can contribute to medicine if it avoids academic and professional trivialisation while simultaneously avoiding immediate political stands on long-range issues. ${ }^{8}$ Clearly, Callahan suggests that the proper aim of medical ethics is to explore long-range issues without proposing immediate solutions to problems.

\section{CRITIQUE}

The problem with position $b$ ), either the application of principles to ethical problems in medicine, or a cautious, long-term development of principles in medical ethics, is that the application of general 
normative ethics theories requires agreement by all concerned regarding the validity of the respective theory. The truth of position $a$ ) leaves this approach in the ruins of relativism. Additionally, general norms lack specificity and cannot contain the clinical variations within their purview. Applying general moral principles to medical problems is destined to fail.

\section{Suggestion \\ I suggest that the fact that physicians must make decisions, willy-nilly, for the good of patients, puts to rest the more abstract leanings of philosophical inquiry. The latter are surely valuable, but not for helpful medical ethics. Position $b$ ), in either form, is rejected on the grounds of the 'pressure to decide', a prominent feature of clinical care. Physicians can- not wait until everyone agrees about which ultimate moral principle to apply to cases to make their decisions. $^{\circ}$}

\section{RANKING}

The clearest example of a non-prescriptive approach to medical ethics (position c)) can be found in the writings of $\mathrm{K}$ Danner Clouser. $\mathrm{He}$ warns about asking more of medical ethics than it can deliver. Medical ethics calls attention to value questions, structures the issues philosophically, and helps to establish priorities of moral principle in resolving conflicts. ${ }^{10}$ Clouser does not argue that medical ethics can help solve cases directly, but views its contribution as a process of ranking moral principles and values. Perhaps because of his non-prescriptive approach, he is less concerned with the possibility of establishing moral principles (position a)), and applying single moral principles to issues (position b)), than with establishing a hierarchy of values which enter medical decision making.

\section{CRITIQUE}

The strength of this position, that medical ethics ought to aim at clarifying and ranking values, is that this procedure is a close analogue to the process of making clinical judgements. ${ }^{11}$ Such a procedure is decidedly helpful in facing difficult moral decisions in the care of patients. However this position stops short of policy recommendations. In a sense, the position truncates the role of medical ethics in actual decision-making by neglecting the legitimate role in policy proposals medical ethics can play. In other words, the position tends to be super-Socratic. Because of this feature, it is an excellent teaching methodology for medical ethics as it stresses the obligation of the health professional to make ethical judgements.

\section{Suggestion}

I suggest an addition to this aim of medical ethics from the argument of Dyck, that the aim of ranking values is not only to highlight the obligation of making moral choices, but also to recommend policy for sets of cases. I would add the possibility $\underset{\Xi}{ \pm} \mathrm{f}$ making consultative recommendations on speçfic cases.

POLICY RECOMMENDATIONS

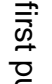

Even though neither MacIntyre nor Marquis he्यूd out much hope for medical ethics, both imply that medical ethics ought to make recommendations \&or solutions to problems. In fact, most medifal ethicists do make such recommendations. ${ }^{12}$ Yet very few explicitly state that policy recommendations are the aim, or at least the substance, of medical ethicis. Position $d$ ) is exemplified, however, in the proposal by Arthur Dyck, that in addition to normative a metaethical concerns, medical ethics must also clude strategies for setting and implementing motal policy. ${ }^{13}$ In addition, Dyck construes moral polisey as 'that portion of the total ethical enterprise In which whatever is known or believed to be true-in normative theory as well as metaethical theory $\overrightarrow{d^{3}}$ applied to specific moral issues and the methouls used to cope with them'. ${ }^{14}$ In explaining how this process works in practice he notes that establish g moral policy requires attention not only to mofal principles but also to the perception of relevaht facts, values, and loyalties. ${ }^{15}$

\section{CRITIQUE}

Establishing a policy recommendation role for medical ethics brings focus to its aim and method. However such an approach might still be viewedaras unduly optimistic by thinkers inclined to moral relativism. How can one assure reasonable acce ance of policy recommendations when these depeñd for their validity on moral principles with which द्glll might not agree?

\section{Suggestion}

To the setting of moral policy recommendation, which Dyck properly indicates involves an understanding of other values and facts of specific cases $I$ would add the requirement which follows frem position $e$ ). Greater focus can be brought to bear medical ethics recommendations when these respect individual cases from which policy is developed. In this way, a group of moral principles 'at risk' in the situation posed by the cases are ranked for their ability to solve the problem equitably. No onge principle is chosen above others, and the differences of cases guarantees that applications of principfes (position $b$ )) are made in an atmosphere of realis Thus while an ethics of medicine might discuss the general problems of abortion from one or anothigr ethical standpoint, medical ethics would examiñe abortion in a range of cases from a birth cont 1 method to serious health hazards. The difference ân recommendations derived from each of thege approaches can be and has been wide. The fornter gives us food for thought. The latter offers a rêf chance for adoption as social policy. 


\section{MEDICAL ACT}

The final position is exemplified by those, like Pellegrino and Cassell, who argue that medical decision-making is inherently a moral enterprise. ${ }^{16}$ The idea here, is that in making clinical decisions, physicians must deal both with the values they profess as well as the values of patients, institutions and society involved in the case. Since the value 'professed' by the profession, healing, is a moral value, decisions with this aim in mind are intrinsically capable of ethical analysis.

\section{CRITIQUE}

The importance of this position for a clinical medical ethics lies in the ability of role-model teachers to overcome the natural tendency to encapsulate clinical judgements within medical factors alone. Evidence exists, as studied by Wendy Carlton in a hospital for one year, that no amount of classroom teaching of ethics will overcome the tendency to reduce moral judgements to ones based merely on clinical signs without the critical attention to values on the part of the role-model teachers. ${ }^{17}$

However, difficulties in this position can occur if one does not properly distinguish moral from ethical activities. If the aim of healing is, indeed, a moral enterprise, this does not mean that all actions of medicine are intrinsically moral. It only means that the actions of medicine are capable of ethical analysis. Nonetheless, establishing medical ethics as a characteristic of medical decision making requires that physicians regard medical ethics as an obligation in making medical decisions. As a consequence, the aim and method of the discipline acquire the kind of specificity discussed in position $d$ ), above.

\section{A clinically based medical ethics}

In this section I will propose an aim of medical ethics and show how this aim can be achieved based on four claims about medical ethics.

\section{CLAIMS REGARDING MEDICAL ETHICS}

From the results of the preceding critique, I would propose as the aim of medical ethics:

\section{To contribute to the resolution of difficult medical dilemmas}

The procedures by which this aim becomes possible are embodied in four claims about medical ethics:

I) The limited norms implied in medical decisions must be developed by a thorough philosophy of medicine. This philosophy of medicine must be completely versed in the clinical practice of medicine. 2) Medical ethicists must know medicine thoroughly enough to make intelligent contributions. Medical ethics can only be helpful to medicine if it is practical and aids solutions to issues. The clinical context is essential.

3) Because medicine is practised by patient-physician interrelation and discussion, and is governed by clinical decision making, medical ethicists can only make useful recommendations on specific cases or classes of cases (moral policy) if they are present for the significant clinical moments in diagnosis, treatment, and management.

4) Medical ethics must incorporate an understanding of ethical theories while establishing new ones based on the developing character of modern medicine and our age.

The implication of each of these claims is that the training of serious medical ethicists must incorporate extensive experience of and reflection on the clinical practice of medicine. A corollary is that medical ethics is not a generalist discipline, as Callahan seems to believe (that role more properly belongs to a newly forming philosophy of medicine). It is a discipline of specialists. Hence it should not be regarded as a branch of philosophy, but a separate theory and practice not unlike medicine itself.

The four claims form the basis of the rest of this paper and the structure of the practicum:

I) The ground of medical ethics in a philosophy of medicine;

2) The practical aim of medical ethics;

3) Settings for ethical issues which involve ethicists in the treatment of patients;

4) New ethical theories.

\section{A clinical practicum in medical ethics}

\section{THE GROUND OF MEDICAL ETHICS}

MacIntyre grounds medical ethics in cultural practices and norms. Because they shift and are relative, he argues that no solutions can be offered. This may be an erroneous assertion. Medical ethics may not be grounded in culture, but in another discipline, that of the philosophy of medicine.

To ground medical ethics in the shifting sands of culture is to forget that the values it explores are not only those of our culture, but also those of the discipline of medicine itself. Education of medical ethicists must include a philosophy of medicine.

It is only against the backdrop of a philosophy of medicine, a critical examination and organisation of medicine's epistemology, its concepts of health and disease, its nature as a discipline, its history, its presuppositions about the nature of human beings, and the values of patients, that medical ethics can be helpful in solving cases. Such a general philosophy of medicine opens the sensitive precincts of medicine to public scrutiny. It might be viewed as the second of Callahan's two orientations, and the first step of 'sensitising' to value questions cited by Clouser. With respect to medical ethics, the primary role of a philosophy of medicine is to articulate a set of limited norms implied in medical decisionmaking. The norms are, of course, limited, because patients, society, institutions, regulations, often 
bring other values than healing to the clinical context. However the norms do make possible attention to the formal conditions of medicine, which, if violated, destroy its aim of healing.

The point is that a philosophy of medicine, still in its infancy, can provide an intermediate set of norms governing the clinical practice of medicine without an appeal to more general ethical norms which are too remote from clinical realities.

Accordingly postgraduate students about to embark on the clinical practicum are trained at the University of Tennessee in Knoxville in philosophy of medicine. They study philosophy of medicine, the history of medical ethics, and medical terminology (to prepare them for their clinical exposure). A reading list has been established to this end.

While some of the practicum students are predoctoral graduate students from Knoxville and other universities, many are post-doctoral professionals who have been teaching or researching medical ethics for some time. The latter are presupposed to have the necessary background.

All students are admitted to the practicum only after recommendation by an admissions committee composed of clinicians and philosophers in the Program on Human Values and Ethics at the University of Tennessee Center for the Health Sciences where the practicum takes place. Judgements are made on evidence of a suitable background education in philosophy of medicine, issues and interests in medical ethics, and clinical maturity.

\section{THE PRACTICAL AIM OF MEDICAL ETHICS}

It is the aim of medical ethics to contribute to the right or good medical decision. Clouser asserts that the aim is to contribute to a just society, but this should be considered more remote and proper to all human endeavour. ${ }^{18}$

In order to effect this aim, training in medical ethics must incorporate both the theory and practice of medicine. Clinical exposure is necessary at the very least for an understanding of clinical judgement, the pressure to decide and its impact on medical and patient values, the art of the experienced clinician, and the role of experiment in modern clinical practice.

While ethics is a discipline which examines the language and value principles of the good, it must deal in a non-obtrusive but definite way with the clinical judgement about what is right to do with or for this patient.

Medical ethics becomes remote, more like pure ethics, insofar as it becomes removed from helpful, clinical concerns. While not demeaning more general interests, these are not the concerns of medical ethics, but of a more general philosophy of medicine as described above.

The clinical practicum is therefore designed for a minimum of three months of clinical exposure. Students are assigned to different and varying clinicians in all fields of medicine, from internists to family practitioners, from house-staff to geneticists, from haematological oncologists to nurse practitioners, from psychiatrists to intensive care nurses, from emergency room personnel to paediatricianss, from social workers to surgeons. These assignments are made easier by cooperative arrangements wh over six hospitals and family practice clinics totallifigg over 5,800 beds.

In every setting, students are expected not ofly to learn about the different specialities and various clinical judgements. They are also expected to of êr helpful insights to clarify and aid in deciding orcterr of priorities of values, which Clouser enumerates?a one role of medical ethics. The students are askd to enter into the treatment decisions for patiegुts and to offer suggestions in many cases, especially those involving establishment of a moral policy. $\overrightarrow{0}$

These are some of the roles of the staff of the Program on Human Values and Ethics, whieh functions as an official advisory service at several $\vec{g} f$ the hospitals involved. Since the clinical practicem is aimed at training medical educators who fill teach pre-professionals or professionals, it is thought best to ask students to imitate the task of the philosophy staff of the programme. In this waycoa practical solution is created in answer to the problegin cited by Marquis.

\section{SETTINGS FOR ETHICAL ISSUES}

Ethical issues vary with patient values and the ting of the delivery of health care. Generally patient values enter decisions more extensively in famity medicine than in a neonate centre. The value sets and priorities change as the setting shifts from primary to secondary to tertiary care. The kindsạof health professionals also change. As the setting shifts from general to more specialised concerns, the kinds and degree of value questions change. Thiss, life-threatening disease is treated in tertiary carre settings where questions about life and death isswes abound. Primary care settings reveal more dialog with patients whose values enter the medieal decision more directly.

No two cases are exactly alike in a primary carre setting; classes of cases are similar in a tertiary che setting. Moreover questions of health policy, syçh as bone marrow transplantation, the moment of death, and so on, appear more often in a tertiary care setting. In order to reduce generalisations bold assertions about medicine, students exposed to services in a large hospital, emergency room and intensive care settings, as well as research medicine, primary care and secondary care servichs in the major fields of medical practice.

During the rotations through these serviogss, students are guided by a clinical coordinator (ußally a medical resident or senior clinician) who, gin turn, works with location coordinators in each of the hospitals and clinics. 
Familiarity with different settings produces a trend away from dangerous and false generalisations about medicine while raising important questions for further research. In every case, clinical exposure raises significant new insights and causes students to reformulate traditional ethical theory. ${ }^{19}$

\section{NEW ETHICAL THEORIES}

In order to ensure the philosophical nature of the clinical residency, the staff of the Program on Human Values and Ethics meets weekly with students to explore research topics, and conducts a weekly seminar on philosophical issues which arise from the clinical experience. Among issues discussed in one year were consent, what constitutes adequate information, a policy on use of life support machines, the nature of a resuscitation team, the critically ill patient, treatment for infection in a case of brain tumour, child-beating, the appropriateness of qualitative hedonism as an ethic for neonate treatment, the seriously ill child and research, and whether medicine is aimed at healing (whether all acts of medicine are moral), to give only a few examples.

Having exposure to the realms and specialities of medicine has led to a reformulation of ethical questions and a search for new theories. Students find that applying ethical theories such as utilitarianism, deontological and natural law ethics is no longer as simple as it once appeared. Medicine itself embodies these theories in various degrees and in different settings. No one ethical theory seems adequate to cover the many branches of medicine explored.

The experience of the inadequacy of previously formulated ethical theories to cover all aspects of modern medicine leads students to re-think their philosophical training, to form more critical judgements of the current literature in medical ethics which itself contains uncritical assertions and generalisations without basis in reality, and to attempt a creation of new theories of ethics. The latter, in turn, feed into the growth of a newly developing discipline, the philosophy of medicine. Perhaps most crucial to new theories of ethics for medicine is the status of health as a value, and its role in determining medical and ethical decisions.

As can be concluded, one's concept of medical ethics influences procedures for training medical ethicists who will in some way be medical educators. While much remains to improve the quality of the clinical experiences, the director and staff of the Program on Human Values and Ethics think this comprehensive plan in clinical medical ethics training is unique and set in the right direction. It develops philosophers capable of speaking knowledgeably about medical-ethical issues while creating interest and capabilities in researching long-range issues.

\section{Conclusion}

While the contributions of students to the treatment of patients is necessarily limited, we find that the physicians and other health professionals involved in their training gradually become more sophisticated about ethical issues in their practice, and encourage medical students and residents to deal with these issues. In the long haul, this reinforcement of ethical concerns by role-model teachers will greatly enhance the quality of care of our patients, and the moral training of ethicists and medical students in the clinical setting.

\section{Acknowledgement}

The clinical practicum herein described is supported by a National Endowment for the Humanities Implementation Grant (ED-32672-78-652) to the Program on Human Values and Ethics, University of Tennessee Center for the Health Sciences, Memphis, and the Philosophy Department, University of Tennessee, Knoxville. It was developed through cooperation between these two institutions. However, the views presented are entirely my own.

\section{References and notes}

${ }^{1}$ Siegler, M (1978). A legacy of Osler: teaching clinical ethics at the bedside. Fournal of the American medical association, 239, 95I-956.

2Shelton, G P (1978). Valedictory for medical residents. Forum on medicine, I, I4-15. Ingelfinger, F J (1975). The unethical in medical ethics. Annals of internal medicine, 83, 264-269.

${ }^{8}$ MacIntyre, A (1975). How virtues become vices. In: Evaluation and explanation in the biomedical sciences, Engelhardt and Spicker (eds.) D Reidel, Dordrecht, p III. Contrast this view with the arguments of Pellegrino, E D (1978). Ethics and the moment of clinical truth. Fournal of the American medical association, 239, 960-96r, on the changes pluralism requires of our view of the methods and aims of ethics. Pellegrino cites the joint programme in medical ethics described herein in his editorial as an example of proper recognition of the clinical basis of medical ethics.

${ }^{4} \mathrm{His}$ position on this point has not changed. MacIntyre, A (1977) argues anew in his Patients as agents. In: Philosophical medical ethics: its nature and significance, Engelhardt and Spicker (eds) D Reidel, Dordrecht, pp 197-212, that the attempts to arbitrate moral claims fail in a pluralistic society which acknowledges no moral authority because disputants can appeal to no common moral footholds.

5Marquis, D B (1976). Medical ethics: danger or help to clinicians? Dialogue: A Kansas journal of health concerns, 3, (4), 38.

'Commenting on Siegler's suggestion that medical ethics be taught, and developed clinically, Jonsen, A (1978), Ethics as immunotherapy, Forum on medicine, I, 52, states that 'I heartily agree (despite the great practical difficulties in following this course)'. 
${ }^{7}$ Hare, R M (1977). Can the moral philosopher help? In: Philosophical medical ethics: its nature and significance, Englehardt and Spicker (eds) D Reidel, Dardrecht, pp 49-61. James Rachels, commenting on this paper (pp 63-69), objects to a purely utilitarian analysis citing other considerations which bear upon the problem.

${ }^{8}$ Callahan, D (1976). The emergence of bioethics. In: Science, ethics and medicine, Engelhardt and Callahan (eds.) Hastings-on-Hudson, N Y Hastings Center, pp x-xxvi.

${ }^{9}$ The serious flaws in position $b$ ) include the following: more weight is given to principles than to realities; conflicts among principles occur because they are derived from different, competing, moral systems; there is a lack of respect for the changing moral character of an age; and there is a lack of respect for the practical nature of ethics itself. This is not to say that analysing difficult ethical problems, such as abortion, from the standpoint of general ethical theories, such as the role against killing, is worthless. Such a process contributes to the general level of ethical discourse in a society. As such, it is extremely valuable. But it is not so valuable as medical ethics, which must have a far more practical aim. It would be best to balance position $b$ ) with $d$ ), such that applying principles would contribute to the creation of a moral policy, as was done by the National Commission for the protection of human subjects whose recommendations on research were adopted by the US Department of Health Education and Welfare.

${ }^{10}$ Clouser, K D (1976). Medical ethics: some uses, abuses and limitations. Arizona medicine, 33, 44-49.
${ }^{11}$ Compare, Thomasma, D C (1978). Training in medical ethics: an ethical workup. Forum on medicine $\frac{\partial}{\partial} \mathbf{I}$, 33-36.

(ب.

${ }^{12}$ For example Paul Ramsey's recommendations chcerning proxy consent. The problem is that, in the main, such recommendations rarely attend to other values and principles in the situation which can $\overline{\text { Tot }}$ t be contained in moral principles.

${ }^{13}$ Dyck, A J (1977). Ethics and medicine. In: Ethic medicine, Reiser, S J, Dyck, A J and Curran, J (eds.) Cambridge, MIT Press, pp II4-122.

${ }^{14}$ Ibid, pp I19-120.

${ }^{15}$ This position is further amplified in Dyck, A J (1977). On human care: an introduction to ethics. Nashvidte, Abingdon Press, pp 19-21.

${ }^{16}$ Pellegrino, E D op cit (see note 3): Cassell, E J (19 Moral thought in clinical practice: applying the abstract to the usual. In: Science, ethics and medicine, Engelhardt and Callahan (eds.), Hastings-ênHudson, Hastings Center, pp 147-160.

${ }^{17}$ Carlton, W (1978). In our professional opinion. . . The primacy of clinical judgement over moral choice. Notre Dame, University of Notre Dame Press.

${ }^{18}$ Clouser, K D p 49, op cit (see note I0).

${ }^{19}$ Our extensive evaluations at the end of the practic@im reveal that each student changed his or her mod about significant medical ethical issues in one theld of the cases listed. The reason cited in every case of a changed point of view is that a more thorough understanding of the clinical setting leads to this change. Furthermore, students spontaneously gife objections to most of the literature on medifal ethics issues as lacking specificity and as being $\bar{O} f$ little or no help. 